\title{
A cross-sectional observational study on knowledge, attitude and practices about indiscriminate use of antibiotics and antibiotic resistance among medical doctors at Sapthagiri Hospital, Bangalore
}

\author{
Navya Teja K.*, Piyali Hazra, L. Padma
}

Department of Pharmacology, Sapthagiri Institute of Medical Sciences and Research Centre, Bangalore, Karnataka, India

Received: 16 September 2019 Accepted: 17 October 2019

\section{*Correspondence to: \\ Dr. Navya Teja K., Email: navyatejakims @gmail.com}

Copyright: (C) the author(s), publisher and licensee Medip Academy. This is an openaccess article distributed under the terms of the Creative Commons Attribution NonCommercial License, which permits unrestricted noncommercial use, distribution, and reproduction in any medium, provided the original work is properly cited.

\begin{abstract}
Background: WHO defines Antimicrobial resistance (AMR) as "the ability of a microorganism to stop an antimicrobial from working against it". The Global burden includes increased morbidity, prolonged illness and a higher mortality rate, along with economic burden. The cause can be tracked down to irrational usage of antibiotics and lack of awareness of rational prescribing practices..

Methods: A cross-sectional questionnaire-based observational study was carried out using a standard pre-validated questionnaire, which was administered to all the medical doctors present in their respective departments during the study period, exploring their knowledge regarding rational antibiotic usage, their attitudes and awareness towards AMR. Informed consent from the participants was obtained verbally, and confidentiality assured. The collected data was analyzed as per descriptive statistics.

Results: Majority of doctors $(91.3 \%)$ have a good knowledge and agree that indiscriminate use of antibiotics leads to antimicrobial resistance. $96.12 \%$ of doctors identify it as a global issue but only $85.5 \%$ consider it a problem in their hospital. Doctors $(78 \%)$ have a positive attitude and do not prefer to prescribe an antibiotic for minor illnesses, but only $40 \%$ think it might contribute to antimicrobial resistance.

Conclusions: This study has demonstrated that doctors have a good knowledge about the emerging problem of antimicrobial resistance, however a minor percentage of doctors fail to acknowledge this at the level of their own hospital. Regular updates on the local antimicrobial resistance rates \& antibiotic stewardship might help to control the global issue of AMR.
\end{abstract}

Keywords: Antimicrobial resistance, Antibiotic stewardship, Rational prescribing

\section{INTRODUCTION}

WHO defines Antimicrobial resistance (AMR) as "the ability of a microorganism (like bacteria, viruses, and some parasites) to stop an antimicrobial (such as antibiotics, antivirals and antimalarials) from working against it". 1

The Global burden caused by AMR is not only restricted to Drug-resistant malaria, tuberculosis or HIV but also associated with many common infections. ${ }^{2}$ Human burden includes increased morbidity, less time with family, prolonged illness, untoward complications and a higher mortality rate. Economic burden being loss of daily wages and work hours, increased cost of diagnostics and treatment. ${ }^{3}$

The problem of AMR can be addressed at many levels, a committed political leadership with strict regulation policies, mandating antibiotic prescriptions at pharmacy outlets or even setting up a hospital antibiotic policy. ${ }^{4}$ But the cause can be tracked down to irrational usage of antibiotics and lack of awareness of rational prescribing practices. 
Over-prescribing, under-prescribing and unnecessary antibiotic combinations contribute to irrational practices. Rational use of antibiotics comprises of right drug at the right dose for the right duration for each patient. Key points to remember would be to consider microbiological susceptibility testing and antibiotic stewardship with standardized hospital antibiotic policies. ${ }^{5}$

Though the concepts of antibiotic resistance and hospital antibiotic policies is generally introduced to the medical students in $2^{\text {nd }}$ year MBBS, how much of it is actually carried forward is a question. Hence, the study was planned for the doctors in an attempt to enlighten the importance of antibiotic stewardship and stimulate the doctors to practice rational prescribing.

Objective of this study was to determine the knowledge, attitude and practice of antibiotic usage and antibiotic resistance among doctors at Sapthagiri Hospital, Bangalore.

\section{METHODS}

A cross-sectional questionnaire-based observational study was carried out over a period of 1 month (September 2018) at Sapthagiri Institute of Medical Sciences and Research Centre, Bangalore. The study instrument is a standard pre-validated questionnaire (Table 1) that was only slightly modified to suit the objective of the current study, with a format that provides information regarding three distinct domains: Knowledge, Attitude, and Practice (KAP). ${ }^{6}$ Aspects that are explored include the knowledge of the respondents regarding rational antibiotic usage, their attitudes and awareness towards AMR and their practices.

Table 1: Questionnaire used for the study.

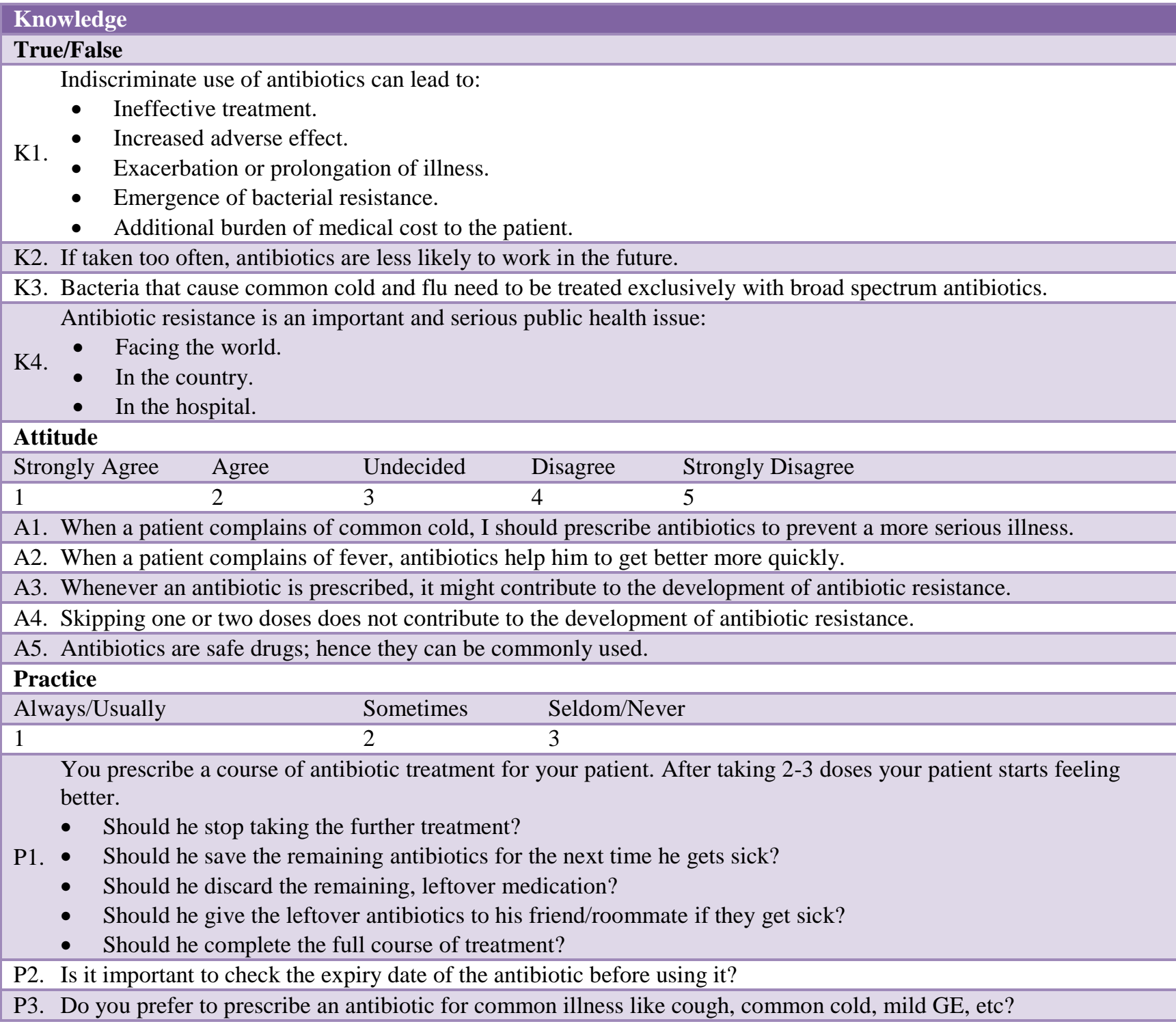


Approval for conducting the study was obtained from the Institutional Ethical Committee. Informed consent from the participants was obtained verbally, and confidentiality assured. The questionnaire was administered to all the medical doctors present in their respective departments during the study period and were willing to participate. Enough time was provided to fill the form, and their queries were attended by the investigator if any.

\section{Statistical analysis}

Questionnaires were collected back, and the data was entered into Microsoft Excel 2013. Analysis was done as per descriptive statistics.

\section{RESULTS}

Out of approximately 120 doctors at our institution, 103 doctors participated in the current study showing a response rate of $85 \%$. Doctors of all ages participated in the study, showing a range of the youngest doctor aged 23 years and oldest aged 69 years. The study comprised of $54(52.4 \%)$ male participants and $49(47.6 \%)$ female participants. Doctors with any medical degree were allowed to participate in the study, and comprised of 4 with MBBS (3.9\%), 71 with MD (68.9\%), 23 with MS (22.4\%), 4 with DNB (3.9\%) and 1 with MRCP (0.9\%). 'True' or 'False' responses were used to interpret the Knowledge. Analysis of attitude was done using five point response Likert scale, and three point response Likert scale for analysing responses of practice based questionnaire.

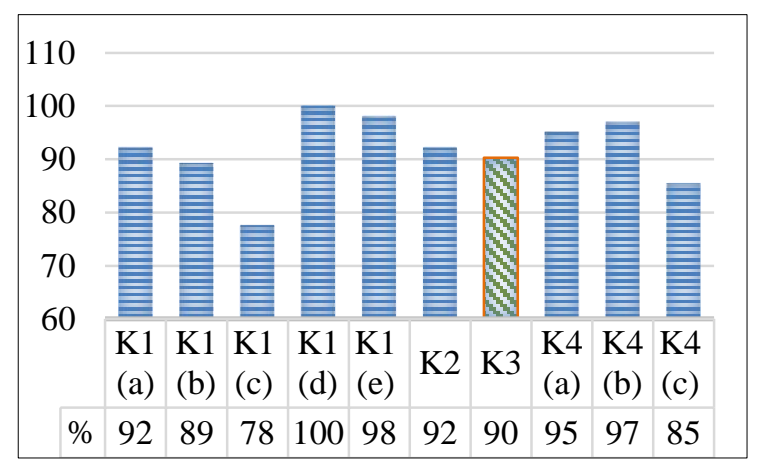

Figure 1: Responses obtained for the knowledge based questionnaire.

Note: Blue colored columns represent the number of 'True' responses while the green colored column represents the number of 'False' responses.

In this study, majority of doctors $(91.3 \%)$ agree that the indiscriminate use of antibiotics leads to antimicrobial resistance. Participants expressed their awareness towards indiscriminate use of antibiotics, and that it might lead to ineffective treatment $(92.23 \%)$, increased adverse effect $(89.32 \%)$, emergence of bacterial resistance $(100 \%)$ and that it imposes additional burden of medical cost to the patient $(98.06 \%)$. But not as many think it might cause exacerbation or prolongation of illness $(77.67 \%), 96.12 \%$ of doctors identify it as a global issue but only $85.5 \%$ consider it a problem when it comes to their own hospital (Figure 1).

Doctors in this study do not prefer to prescribe an antibiotic for minor illnesses $(94.17 \%)$ or fever $(64.08 \%)$ and believe that they cannot be used commonly considering them to be safe $(74.76 \%)$. Nevertheless, only $51.45 \%$ of them think that antibiotic doses should not be skipped, and only $39.8 \%$ of doctors in this study think it may contribute to antimicrobial resistance whenever an antibiotic is prescribed (Figure 2).

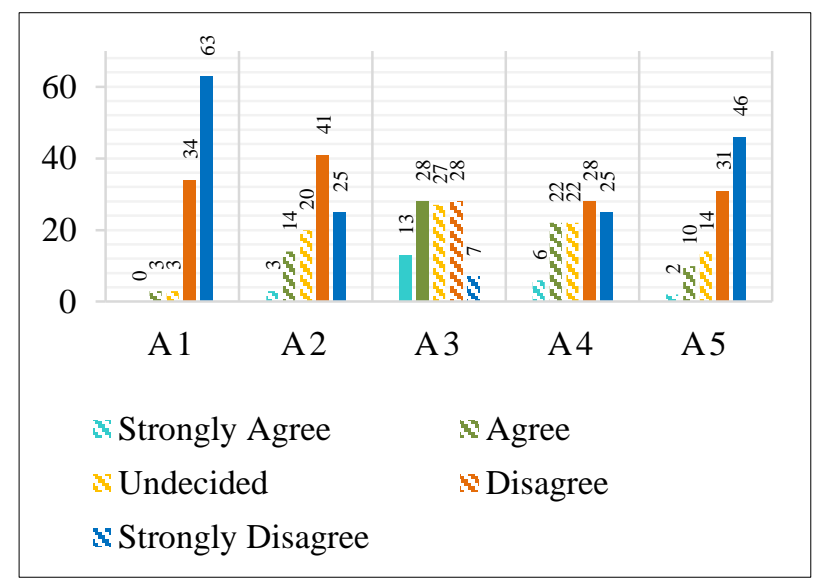

Figure 2: Responses obtained for the attitude based questionnaire.

Total $95.15 \%$ of the doctors in this study tend to advise their patients to complete the course even if they start feeling better after a few doses. But a few (43.69\%) feel it would be fine for them to discard the antibiotics after they start feeling better. All of the participants (100\%) agree that it is important to advise the patient to check for the expiry date of the antibiotic before use. Only $1.94 \%$ of the doctors felt the need to prescribe antibiotics for common illness like cough, common cold, mild GE, etc (Figure 3).

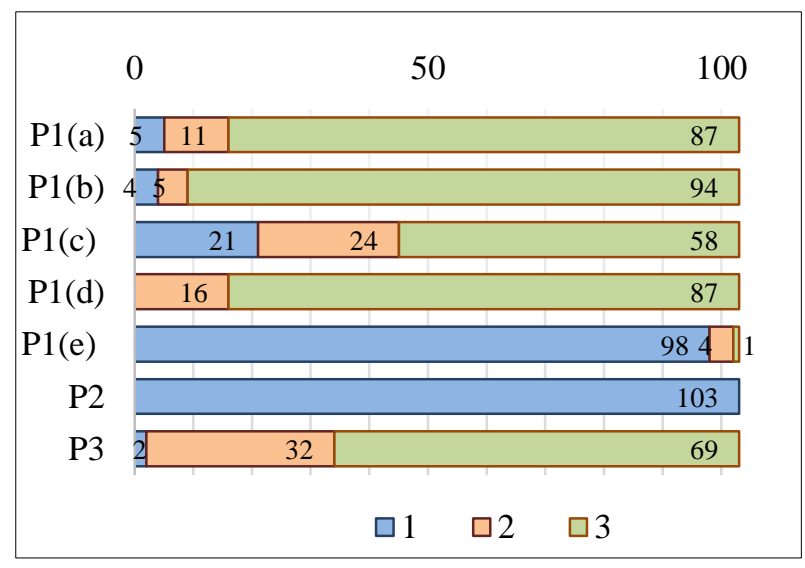

Figure 3: Responses obtained for the practice based questionnaire. 


\section{DISCUSSION}

KAP studies act as a tool to provide valuable insights about various scenarios (in case of this study: antibiotic resistance), to give basic platform on which author can design interventions and antibiotic policies based on the current mindset of doctors and requirement of the community. ${ }^{7}$

Antimicrobial resistance (AMR) is not a sudden phenomenon, but evolving over decades with increasing number of bacteria acquiring resistance to newer antimicrobial agents. Many studies have been depicting the changing trends in bacterial resistance and creating awareness of this global issue. WHO has estimated that the resistance to specified antimicrobial agents is exceeding $50 \%$ especially for organisms like E. coli, $K$. pneumoniae and $S$. aureus, that are commonly isolated in community acquired infections. ${ }^{3}$

Majority of doctors now believe that overuse of antibiotic prescriptions, self-medication and irrational use of broad spectrum antibiotics due to their easy availability have led increased resistance to antibiotics. ${ }^{8}$ Lack of sufficient knowledge among nursing staff and pharmacist leading to insufficient dosing of antibiotic and prolonged duration of treatment can also be considered. Doctors now believe that formulating rigid guidelines, resistance data and focusing on education of target population might help to curb the problem. ${ }^{9}$

Most of the doctors acknowledge AMR as global issue, but fail to recognize the same at the level of their own institute/hospital, leading to injudicious use of antibiotics, further contributing to the issue. In this study only $85.5 \%$ of the doctors feel that AMR is an issue in their hospital that is comparable to the results of a study by Padmanabha et al. ${ }^{6}$

More awareness and education is needed to change the attitude of both doctors and patients that it is important to complete the course of antibiotics prescribed. The gut flora act as a major reservoir of resistant bacteria, capable of spreading the same to the pathogenic strains. ${ }^{10}$ Only a few doctors $(51.45 \%)$ think that antibiotic doses should not be skipped.

Rational prescribing habits of antibiotics should be matched with microbiological susceptibility testing and infection control, which would help to combat the problem of AMR. Early and timely interventional programs and interactive learning of rational prescribing habits would help to curb the growing resistance as suggested by Khan et al. ${ }^{11}$

Updating and creating awareness about the current scenarios through continued medical education and workshops on AMR and hospital antibiotic policies help a doctor towards rational antibiotic usage, as opined by the results of this study similar to another study by Ghosh et al. $^{12}$

\section{CONCLUSION}

From this study, it can be concluded that study has gathered useful information testing the knowledge, attitude and practices of doctors in northern Bangalore. It has demonstrated that the doctors have a good knowledge and awareness about the emerging problem of antimicrobial resistance, however a minor percentage of doctors fail to acknowledge the same at the level of their own hospital. CMEs and regular meetings, stressing on the importance of antibiotic stewardship might help to improve the perception of the issue. The study has also helped to identify gaps in the attitude and practicing habits about the rational prescribing of antibiotics. Regular updates on the local antimicrobial resistance rates, a rigid hospital antibiotic policy revised from time to time and giving proper instructions to patients while prescribing antimicrobials, might help to control the global issue of AMR.

Limitations of the current study targeted the doctors of the institution, it would have been better to conduct a similar study among the interns, so as to create awareness and train them at the grass root level to have a better impact on the mindset of young doctors.

\section{ACKNOWLEDGEMENTS}

Authors would like to thank all the faculty of all the preclinical, paraclinical and clinical departments of Sapthagiri Institute of Medical Sciences and Research Centre, Bangalore, for their co-operation in participating in this study.

\section{Funding: No funding sources}

Conflict of interest: None declared

Ethical approval: The study was approved by the Institutional Ethics Committee

\section{REFERENCES}

1. World Health Day 2011-Antibiotic resistance: No action today, no cure tomorrow. Available at: http://www.who.int/world-health-day/2011/en/ Accessed: 11 August 2018.

2. Kumar SG, Adithan C, Harish BN, Sujatha S, Roy G, Malini A. Antimicrobial resistance in India: A review. J Nat Sc Biol Med. 2013;4:286-91.

3. World Health Organization, editor. Antimicrobial resistance: global report on surveillance. Geneva, Switzerland: World Health Organization. 2014:232 .

4. Ghosh A, Deb T, Ghosh S. Knowledge, attitudes and practice survey about antimicrobial resistance and prescribing among physicians in a tertiary care teaching hospital in Eastern India. Int J Basic Clin Pharmacol. 2016;5:180-7. 
5. World Health Organization, editor. The evolving threat of antimicrobial resistance: options for action. Geneva, Switzerland: World Health Organization. 2012:119.

6. Padmanabha TS, Nandini T, Manu G, Madhav Savkar, Ravi M. Knowledge, attitude and practices of antibiotic usage among the medical undergraduates of a tertiary care teaching hospital: an observational cross-sectional study. Int $\mathrm{J}$ Basic Clin Pharmacol. December 2016; 5(6):2432-7.

7. Thriemer K, Katuala Y, Batoko B, Alworonga JP, Devlieger $\mathrm{H}$, Van Geet $\mathrm{C}$, et al. Antibiotic prescribing in DR Congo: a knowledge, attitude and practice survey among medical doctors and students. PloS One. 2013;8(2):e55495.

8. Shanthi M, Sekar U. Multi-drug Resistant Pseudomonas aeruginosa and Acinetobacter baumannii infections among hospitalized patients: risk factors and outcomes. JAPI. 2009;57:636, 63845 .

9. Aggarwal S, Mathew J, Singh H, Sharma V. Attitude and perception of junior resident doctors' regarding antibiotic resistance - a pilot study. J Acute Dis. 2014;6-9.
10. Bala R, Singh H, Kaur K, P Girish, Kohli K. Knowledge and attitude towards antimicrobial selfmedication usage: a cross sectional study among medical and nursing students. Int $\mathrm{J}$ Basic Clin Pharmacol. 2013;2:428-32.

11. Khan AA, Banu GK. Antibiotic Resistance and Usage-A Survey on the Knowledge, Attitude, Perceptions and Practices among the Medical Students of a Southern Indian Teaching Hospital. J Clini Diagnostic Res. 2013;7(8):1613-6.

12. Srinivasan A, Song $X$, Richards A, SinkowitzCochran R, Cardo D, Rand C. A survey of knowledge, attitudes, and beliefs of house staff physicians from various specialties concerning antimicrobial use and resistance. Archi Internal Med. 2004;164(13):1451-6.

Cite this article as: Teja NK, Hazra P, Padma L. A cross-sectional observational study on knowledge, attitude and practices about indiscriminate use of antibiotics and antibiotic resistance among medical doctors at Sapthagiri Hospital, Bangalore. Int J Basic Clin Pharmacol 2019;8:2609-13. 